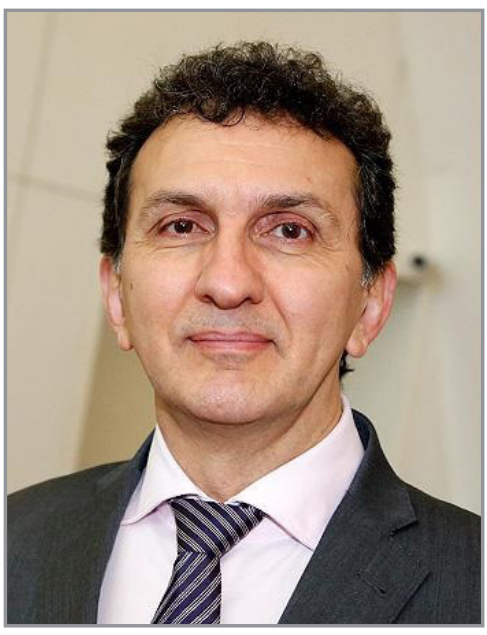

\title{
BrJAC celebrating 10 years
}

\author{
Pedro Vitoriano Oliveira iD \\ Departamento de Química Fundamental - Instituto de Química \\ Universidade de São Paulo \\ São Paulo, SP, Brazil
}

In the year 2020 BrJAC - the Brazilian Journal of Analytical Chemistry-celebrates its $10^{\text {th }}$ anniversary. It is gratifying for me to have participated in this project from the beginning. It is also satisfying to see, 10 years later, that BrJAC can be accessed all over the world from different scientific databases (Web of Science, Scopus, CAplus and Google Scholar). For this, it is essential to express our gratitude to the Editor-in-Chief, Associate Editors, Advisory Board, the outstanding reviewers as selected by the Editorial Group and also the Authors for their significant contributions and believing in this scientific journal; the success of BrJAC has been driven by all these players. BrJAC maintains its original proposal, which is publishing articles, technical notes, reviews, interviews with senior researchers, letters, points of view and sponsor reports. The main focus of the interviews is directed at the illustrated trajectories, experiences, difficulties and achievements of senior researchers, whose stories serve as encouragement and reference for young scientists and professionals in related fields. With the letters and points of view, the objective is communication and discussion between different readers in the academic and industrial sectors. Over these 10 years, multidisciplinary subjects involving analytical chemistry have been published, directed at the qualitative and quantitative demands required every day in our modern world, either by the fast action of high-tech industries, which seek quality in processes and products, or by successful insertion of proposed modern methods using new instrumentation in the fields of medicine, biology, biochemistry, pharmaceuticals, food, agriculture and the environment, etc. A new decade begins for BrJAC and, with due responsibility, we will help to disseminate quality analytical chemistry to Brazil and other parts of the world. We hope you enjoy the contributions of this $25^{\text {th }}$ volume of BrJAC. 